\title{
DETERMINATION OF INTERFACES IN SOIL LAYERS BY SOUND WAVE ANALYSIS WITH CONE PENETRATION TESTS
}

\author{
Huei-Wen Chang \\ Department of Civil Engineering, National Central University, Jhongli, Taiwan, R.O.C \\ Tseng-Hung Chang \\ Department of Civil Engineering, National Central University, Jhongli, Taiwan, R.O.C., b1230583@ms56.hinet.net \\ Viet-Tuong Nguyen \\ Department of Civil Engineering, National Central University, Jhongli, Taiwan, R.O.C. \\ Chih-Wei Wang \\ Department of Civil Engineering, National Central University, Jhongli, Taiwan, R.O.C.
}

Follow this and additional works at: https://jmstt.ntou.edu.tw/journal

Part of the Civil and Environmental Engineering Commons

\footnotetext{
Recommended Citation

Chang, Huei-Wen; Chang, Tseng-Hung; Nguyen, Viet-Tuong; and Wang, Chih-Wei (2010) "DETERMINATION OF INTERFACES IN SOIL LAYERS BY SOUND WAVE ANALYSIS WITH CONE PENETRATION TESTS," Journal of Marine Science and Technology. Vol. 18: Iss. 5, Article 6.

DOI: 10.51400/2709-6998.1909

Available at: https://jmstt.ntou.edu.tw/journal/vol18/iss5/6

This Research Article is brought to you for free and open access by Journal of Marine Science and Technology. It has been accepted for inclusion in Journal of Marine Science and Technology by an authorized editor of Journal of Marine Science and Technology.
} 


\section{DETERMINATION OF INTERFACES IN SOIL LAYERS BY SOUND WAVE ANALYSIS}

WITH CONE PENETRATION TESTS

\section{Acknowledgements}

The authors would like to thank the National Science Council of the Republic of China, Taiwan, for financially supporting this research under Contract No. NSC 89-2211-E-008-098. 


\title{
DETERMINATION OF INTERFACES IN SOIL LAYERS BY SOUND WAVE ANALYSIS WITH CONE PENETRATION TESTS
}

\author{
Huei-Wen Chang*, Tseng-Hung Chang*, Viet-Tuong Nguyen*, and Chih-Wei Wang*
}

Key words: cone resistance, sound wave, RMS of sound pressure, HHT.

\begin{abstract}
This experimental study precisely identifies the soil layer interface using sound signals collected during cone penetration tests (CPTs). Using the high sensitivity of the sound sensor at the cone tip, this study effectively increases the accuracy in identifying the soil interface location. Shiluo sand and Jhongda Lateritic soil were used to construct large-scale soil layers. An acoustic CPT was applied to determine sound pressure and its root mean square (RMS). The Fourier spectrum and Hilbert-Huang transform (HHT) method were utilized and compared in their ability to analyze sound signals. The HHT method with a local energy-instantaneous frequencytime distribution performed well. According to analytical results, both the RMS and HHT methods are more effective than cone resistance in locating the soil interface. The major contribution of this study is that it uses the RMS of sound wave as a more accurate, effective and easy method for exploration of soil distribution and detection of soil interfaces.
\end{abstract}

\section{INTRODUCTION}

The cone penetration test (CPT) is widely performed in the field during soil exploration work. The CPT has excellent accuracy in the acquisition of soil parameters in the field, which are difficult to obtain in a laboratory, and provides continuous information for soil depths. In comparison with other field tests, the CPT is convenient and provides data for a detailed understanding of various soil properties. Cone resistance $\left(q_{c}\right)$ is the principal measurable parameter obtained during the CPT. However, to precisely identify soil layer interfaces, cone resistance cannot meet the requirement of accuracy because $q_{c}$ can only be developed when the same type of soil surrounds the cone tip at a depth 5-10 times the

Paper submitted 04/07/09; accepted 09/05/09. Author for correspondence: Tseng-Hung Chang (e-mail: b1230583@ms56.hinet.net).

*Department of Civil Engineering, National Central University, Jhongli, Taiwan, R.O.C. cone diameter. This enclosure can lead to mistakes in locating the soil interface, and incorrect assessment of soil properties. Furthermore, the CPT has difficulty detecting the existence of thin soil layers and their properties. In the case of a confined aquifer in a soil stratum, inaccurate positioning of the interface can result in aquifer destruction during excavation and increase the risk of heaving and quicksand development. This study locates the soil interface with increased precision using a novel acoustic cone penetration method. Interface identification accuracy is increased by using a highly sensitive sound sensor on the cone tip.

Many possible mechanisms, such as crystal failure, induced cracking, extrusion, moving dislocations, phase variation, and twinning, can produce sound waves in soil. The development of cracks in brittle materials (such as rock), and the squeezing of and friction in coarse grain materials (such as sand) are the principal mechanisms generating sound wave in soils. Koerner et al. [8] utilized spectrum analysis to determine the predominant frequency $(f)$ of sound waves in soil in the range of $0-40 \mathrm{kHz}$ (in direct shear tests); the predominant frequency band of sound waves in unconfined compression and triaxial tests was $250 \mathrm{~Hz}$ to $8 \mathrm{kHz}$.

During acoustic cone penetration in soils, sound waves are generated due to soil particles rolling and sliding on the cone surface or particles being crushed. The sound signals generated are carefully acquired by a data acquisition system. In this study, the variation in sound signals for different soil layers was monitored and analyzed. The measured sound waves were processed to yield some significant parameters - the root mean square (RMS), fast Fourier transform (FFT) - for obtaining the time history of sound pressure, the RMS of sound pressure $\left(P_{R M S}\right)$, and the Fourier spectrum. Based on sound wave responses at different soil interfaces, the interrelationship among cone resistance, sound waves and soil properties was established, facilitating accurate determination of the soil interface.

\section{APPLICABILITY OF FFT AND HHT}

\section{Applicability of Fast Fourier Transform}

Fourier transformation is effective for extremely general conditions; however, some significant restrictions exist in 


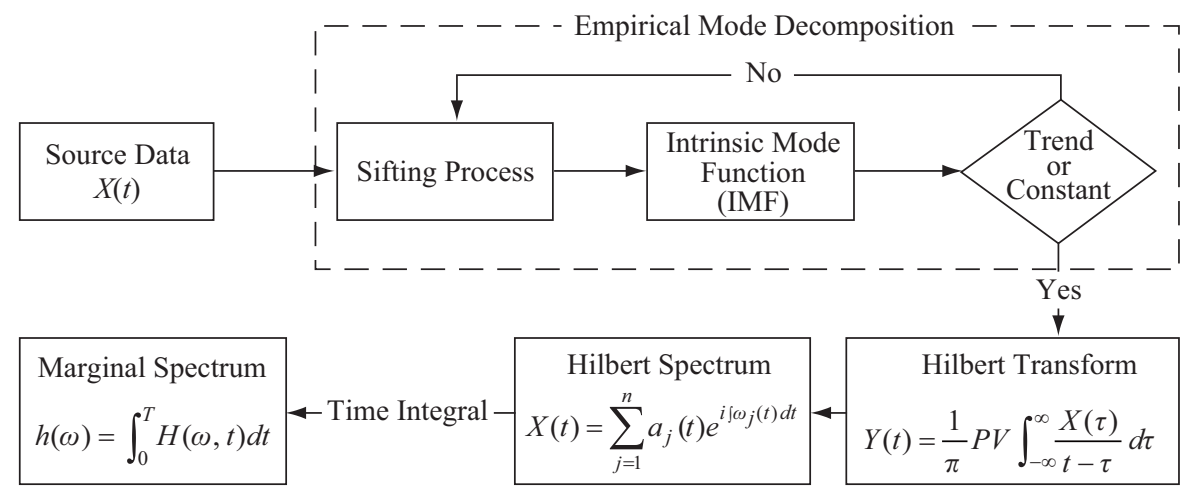

Fig. 1. Framework of the HHT (After Hsieh [5]).

Fourier spectral analysis. For example, the system must be linear and systematic data must be periodic or stationary; otherwise, the yielded spectrum may be beyond physical meaning. Unfortunately, most natural phenomena are transient, aperiodic and non-stationary (e.g., sound waves in soils). These stationary and linearity assumptions can cause incorrect result interpretations. In other words, Fourier analysis may be unsuitable for this type of non-stationary data. The major reason is that in Fourier analysis, a spectrum is defined globally using a set of uniform harmonic function components. Hence, to simulate non-stationary data, many assumed harmonic function components are needed to approximate data, which spreads energy over an enlarged frequency range. Based on the conservation of energy, the actual energy density in the frequency domain cannot be expressed by these assumed harmonic function components or by the large spectrum bandwidth $[1,13]$. Thus, utilizing the FFT to deal with such sound signals is inappropriate. A new analytical technique called the HilbertHuang transform (HHT), which was developed by Huang and Shen [6], is therefore applied to analyze sound waves. Via analysis, the content and significance of sound waves were determined and the depth of the interface in soil layers was identified accurately.

\section{Applicability of the Hilbert-Huang Transform}

\section{1) Theory of the HHT}

Huang et al. [7] conducted a study of empirical mode decomposition (EMD) and used the Hilbert spectrum for nonlinear and non-stationary time series analysis. This new method, called the HHT, is based on EMD, its core, for analysis, such that any complex dataset can be decomposed into a finite small number of intrinsic mode functions (IMFs) that accommodate the well-behaved Hilbert transforms. Based on the local characteristic time scale of data, the HHT can be applied to nonlinear and non-stationary processes. These IMFs constitute the basis of decompositions that are complete and practically orthogonal. With the HHT, intrinsic mode functions yield instantaneous frequencies as functions of time that accurately identify imbedded structures. The final output is a Hilbert spectrum with an energy-frequency-time distribution.
In this study, the major innovations are the introduction of intrinsic mode functions based on local properties of a signal, thereby making the instantaneous frequency meaningful, and the introduction of instantaneous frequencies for complex datasets, thereby eliminating the need for spurious harmonics to represent nonlinear and non-stationary signals. Additionally, as the Hilbert spectrum is defined, the marginal spectrum can also be defined. The marginal spectrum is a measure of the total magnitude (or energy) contribution based on each frequency value, which represents the cumulative amplitude over the entire data range in a probabilistic sense. The differences between, and advantages and disadvantages of the HHT and FFT can be identified and compared using the marginal spectrum and Fourier spectrum. Figure 1 shows the framework of the HHT structure (after Hsieh [5]).

\section{2) Applications of the HHT}

In analyzing seismic data using the HHT, Bi [1] concluded that (1) the energy and frequency of IMF components obtained by HHT analysis varied over time, while those acquired by FFT analysis remained constant. Thus, in terms of adaptability, the FFT was limited. (2) In the Fourier spectrum, highfrequency energy is amplified, which reduces low-frequency energy and results in analytical difficulties. (3) Notably, the HHT has a higher resolution than the FFT. Wang [15] obtained similar analytical results.

Yang [18] applied the HHT to determine the pressure distribution on the surface of a three-dimensional building model under uniform wind flow and periodically varying winds speeds. By using EMD, data were decomposed into a few IMF components ranging from high to low frequencies. Several physical meanings and specific IMFs were selected for calculation to derive the instantaneous frequency, energy of cyclical gusts and swirl diffuseness. The energy-frequency-time distribution indicates the distribution of a particular frequency in the timedomain; such an observation cannot be obtained using the FFT.

\section{EXPERIMENTAL PROCEDURE}

In this study, the acoustic CPTs were carried out for dif- 
Table 1. The basic physical properties of Shiluo sand.

\begin{tabular}{|c|c|}
\hline Specific gravity & 2.66 \\
\hline Moisture content $(\%)$ & 5.37 \\
\hline $\mathrm{D}_{50}(\mathrm{~mm})$ & 0.32 \\
\hline Maximum dry unit weight $\left(\mathrm{kN} / \mathrm{m}^{3}\right)$ & 17.46 \\
\hline Minimum dry unit weight $\left(\mathrm{kN} / \mathrm{m}^{3}\right)$ & 13.34 \\
\hline Particle shape & flat sub-sharp \\
\hline Unified soil classification & SP \\
\hline
\end{tabular}

Table 2. The basic physical properties of Jhongda Lateritic soil.

\begin{tabular}{|c|c|}
\hline Specific gravity & 2.68 \\
\hline Moisture content (\%) & 35.25 \\
\hline Liquid limit (\%) & 42.0 \\
\hline Plastic limit (\%) & 25.3 \\
\hline Plastic index & 16.7 \\
\hline Sand content (\%) & 11.52 \\
\hline Silt and clay content (\%) & 88.48 \\
\hline Unified soil classification & CL \\
\hline
\end{tabular}

ferent soil layers using a large-scale indoor test pit. The responses of sound waves during the penetration process were acquired and processed to locate the interface between different soil layers. Test materials, equipment, procedure and sound signal processing are described as follows.

\section{Test Materials}

The sand used in this study is Shiluo sand obtained from the Choshui River, Yunlin County, Taiwan. Shiluo sand is classified as poorly graded sand (SP). Table 1 lists the basic physical properties of Shiluo sand. The clay sample consisted of Jhongda Lateritic soil (CL), which was acquired from the campus of National Central University, Taiwan. Table 2 lists the basic physical properties of Jhongda Lateritic soil. Figure 2 shows the grain-size distributions of Shiluo sand and Jhongda Lateritic soil.

\section{Experimental Equipment and Instruments}

The experimental equipment and instruments used in the tests were as follows.

(1) Cone penetration device: With a reaction seat (Fig. 3(a)), the cone penetration device developed by Chang and $\mathrm{Ou}$ [2] was used in experiments.

(2) Acoustic cone: Fig. 3(b) shows a schematic of the acoustic cone developed by Chuang [3]. A microphone was placed at the cone tip such that sound waves were measured and acquired during the cone penetration process. Cone resistance was also measured using a load cell installed at the cone shaft end. Massarsch [10] noted that high-frequency sound waves decay rapidly, and are

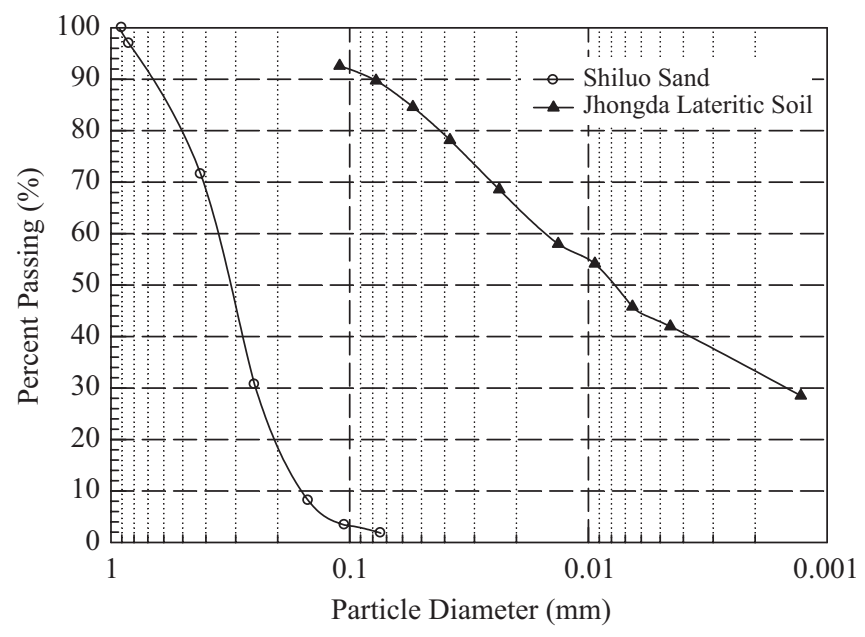

Fig. 2. Grain-size distribution curves in the soil samples.

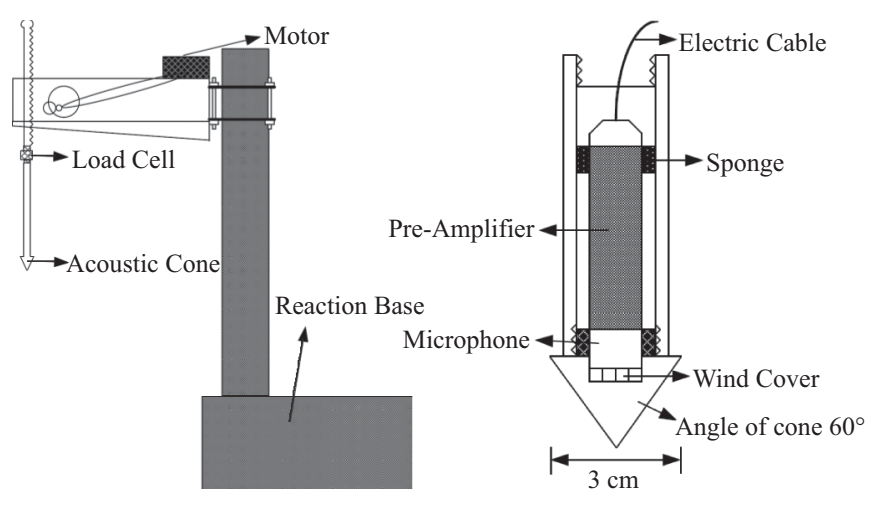

(a) reaction seat

(b) acoustic cone

Fig. 3. Lay out of the reaction seat and the acoustic cone.

unaffected by background noise. Generally, sound waves can be recorded easily when they are close to the microphone. This is the main reason for choosing the proper position of the microphone. Massarsch also demonstrated that the amplitudes of sound waves in sand are roughly 100 times greater than those in clay. Tringale [13] obtained similar experimental results.

(3) Large-scale test pit: The large-scale indoor test pit was constructed of reinforced concrete; it was $3 \mathrm{~m}$ deep and $6 \mathrm{~m}$ long and wide. Figure 4 shows a longitudinal section of the test pit. Soil samples were saturated with water pumped through pipes located on the test pit walls.

(4) Data acquisition system for sound signals: This system comprised a microphone, mini preamplifier, dedicated power supply, signal capture card and software.

\section{Test Procedure}

The soil sample with both a Shiluo sand layer and Jhongda Lateritic soil layer was constructed in the test pit for the acoustic CPTs. 

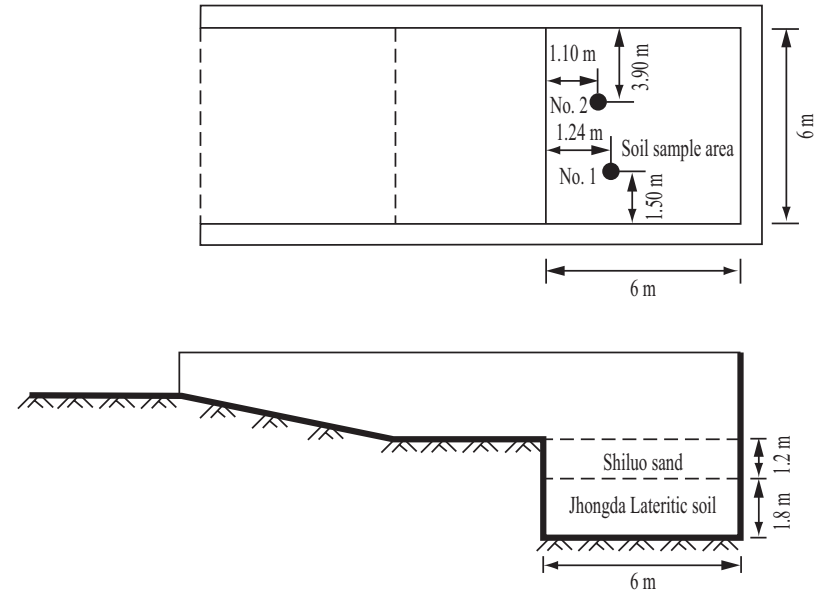

Fig. 4. Longitudinal section of the large-scale test pit.

\section{1) Preparation of Soil Layers}

A. Jhongda Lateritic soil was first placed in the test pit and compacted uniformly to a thickness of roughly $1.8 \mathrm{~m}$.

B. Clean water was then fed into the Jhongda Lateritic soil layer from the pipes located at four corners of the test pit to saturate the soil for 30 days. The groundwater table was located $1.2 \mathrm{~m}$ below the ground surface. The degree of saturation for Jhongda Lateritic soil was approximately $93 \%$ with a moisture content of $35.25 \%$, dry unit weight of $13.02 \mathrm{kN} / \mathrm{m}^{3}$ and specific gravity of 2.68 .

C. A 1.2-m-thick uniform Shiluo sand layer was added on top of the Lateritic soil layer. The dry unit weight and relative density of Shiluo sand was $15.27 \mathrm{kN} / \mathrm{m}^{3}$ and $54 \%$, respectively.

D. According to the formula developed by Hazen [4], the height of the capillary rise $\left(h_{1}\right)$ in soil was estimated by

$$
h_{1}(m m)=\frac{C}{e D_{10}}
$$

where $D_{10}$ is the effective particle size (mm), $C$ is a constant that varies at $10-50 \mathrm{~mm}^{2}, e$ is the void ratio. In this study, the $D_{10}$ of sand was roughly $0.16 \mathrm{~mm}$ and $e$ was about 1.02 . If we assume that $C$ was $30 \mathrm{~mm}^{2}$, then the capillary rise $h_{1}$ was $184 \mathrm{~mm}$, roughly $18 \mathrm{~cm}$. Additionally, a comparison of experimental results obtained by Wang [16] and Lin [9] indicates that the cone resistance and RMS of sound pressure in saturated sand are slightly lower than those for dry sand. Compared with these differences between Shiluo sand and Jhongda Lateritic soil, the difference between saturated sand and dry sand is negligible. Hence, capillarity did not affect study results.

\section{2) Acoustic Cone Penetration Test Procedure}

The penetration stroke of the acoustic cone penetration device was $0.6 \mathrm{~m}$ for each stage. The test procedure was as follows.

A. A small $0.25 \mathrm{~m}$ deep hole is made in the top of the soil sample.

B. The acoustic cone is placed inside the hole for the first stage of the penetration test; the cone had a rate of $2 \mathrm{~cm} / \mathrm{sec}$. The cone tip penetrated to a depth of roughly $0.75-0.85 \mathrm{~m}$ from the top surface.

C. An extension rod was connected to the cone in the second stage of the penetration test. The cone was driven into the soil layer to a depth of $1.35 \mathrm{~m}$.

D. Using the same procedure, two sets of tests (tests No. 1 and No. 2) were performed on the same soil sample at different locations. Figure 4 shows the locations of CPTs No. 1 and No. 2. During penetration, sound waves and cone resistances at each depth $(D)$ were measured and acquired by the data acquisition system for subsequent processing.

\section{Sound Signal Processing}

The RMS of sound pressure is defined as the square root of the sum of all squares of each measured transient sound pressure. The average value within the sampling period is adopted, and the square root of this average is derived by (2). The RMS of average sound pressure is always positive because items are squared. Restated, the RMS of sound pressure is the strength of a sound wave as a type of non-zero value [17].

$$
P_{R M S}=\left[\frac{1}{T} \int_{0}^{T} P^{2}(t) d t\right]^{0.5}
$$

where $P(t)$ and $T$ are sound pressure amplitude and period, respectively. In this study, the RMS of sound pressure is calculated once at an interval of $5 \mathrm{~mm}$ along the penetration depth. At a penetration depth of $0.5 \mathrm{~m}, 100$ data points describe the variety of $P_{R M S}$ during the penetration process. This method is called the mobile RMS sound-pressure method.

Tanimoto and Tanaka [12] demonstrated that the frequencies of sound waves are generally $<20 \mathrm{kHz}$ in sandy soil. In accordance with the Nyquist-Shannon sampling theorem, a sampling rate of $40 \mathrm{kHz}$ is utilized to avoid the aliasing phenomenon.

\section{EXPERIMENTAL RESULTS AND ANALYSIS}

In the acoustic CPTs, sound signals were processed and analyzed in terms of cone resistances, the RMS of sound pressures, Fourier spectrum and Hilbert spectrum to locate the interface depth of soil layers.

\section{Cone Resistances}

When a cone penetrates soil, stress resistance acting on the cone is similar to the stress distribution induced by the endbearing pile. The shear resistance in soils around the cone shaft affects the variety of cone resistances. Schmertmann 


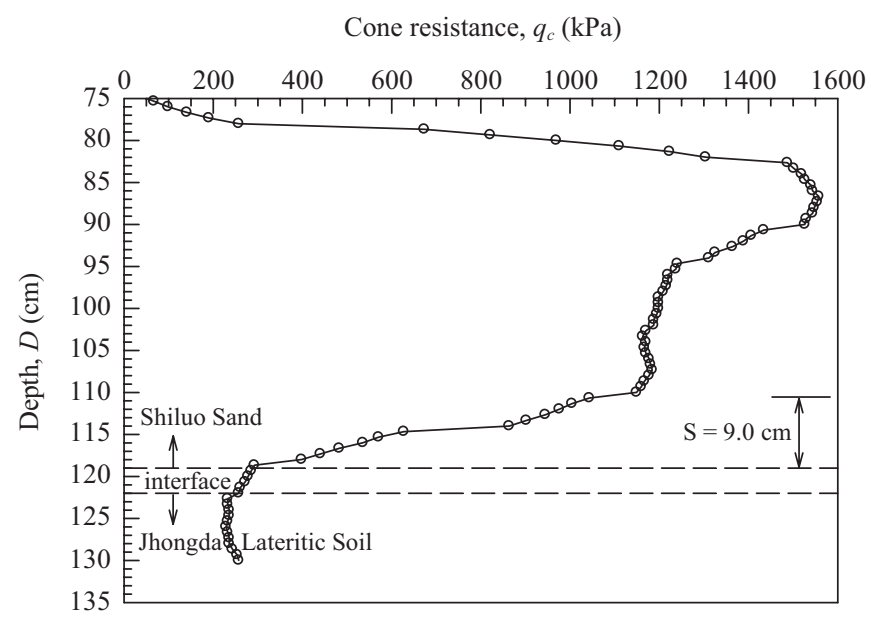

Fig. 5. Relationship between cone resistance and depth for test No. 1 .

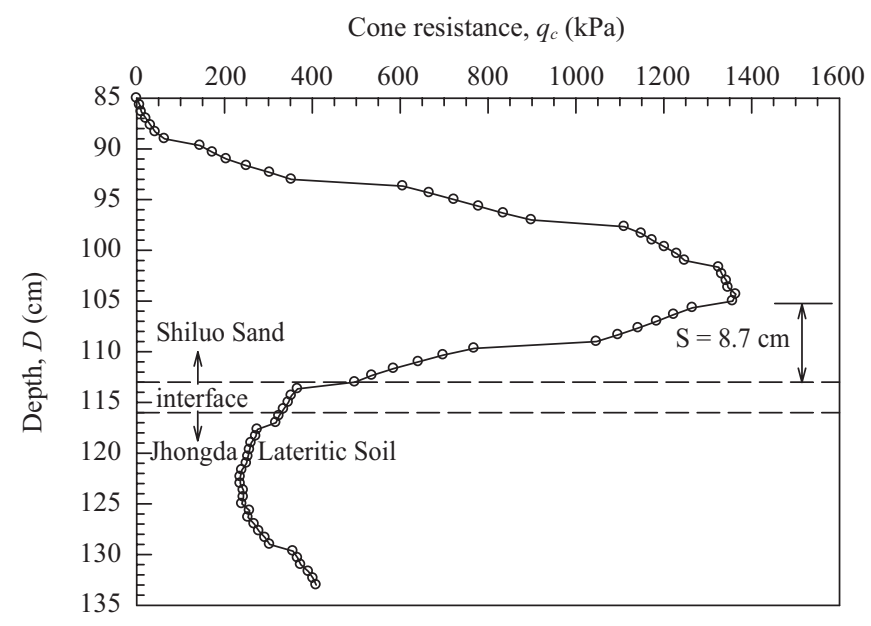

Fig. 6. Relationship between cone resistance and depth for test No. 2 .

[11] indicated that cone resistance is affected by soil thickness below the cone tip, which is about 10-15 times the cone diameter. Hence, the minimum measurable thickness of the sand layer is approximately $30-50 \mathrm{~cm}$.

In this study, the major part of the penetration test begins at about $75-85 \mathrm{~cm}$ below the top surface of the soil layers. When the penetrations were completed, the sand layer at the penetrated position was dug out to confirm the interface depth and for comparison with penetration test results. The depths of the actual interfaces between the two layers were $119-122 \mathrm{~cm}$ and 113-116 cm for tests No. 1 and No. 2, respectively.

Figures 5 and 6 show the cone resistances along the penetration depths for tests No. 1 and No. 2, respectively. The cone resistance in the Shiluo sand layer initially increases as penetration depth increases, and peaks before the acoustic cone reaches the interface. The cone resistance then decreases as penetration depth increases. Cone resistance declined markedly, even when the cone tip had not reached the interface. This phenomenon may generate some error in locating the soil

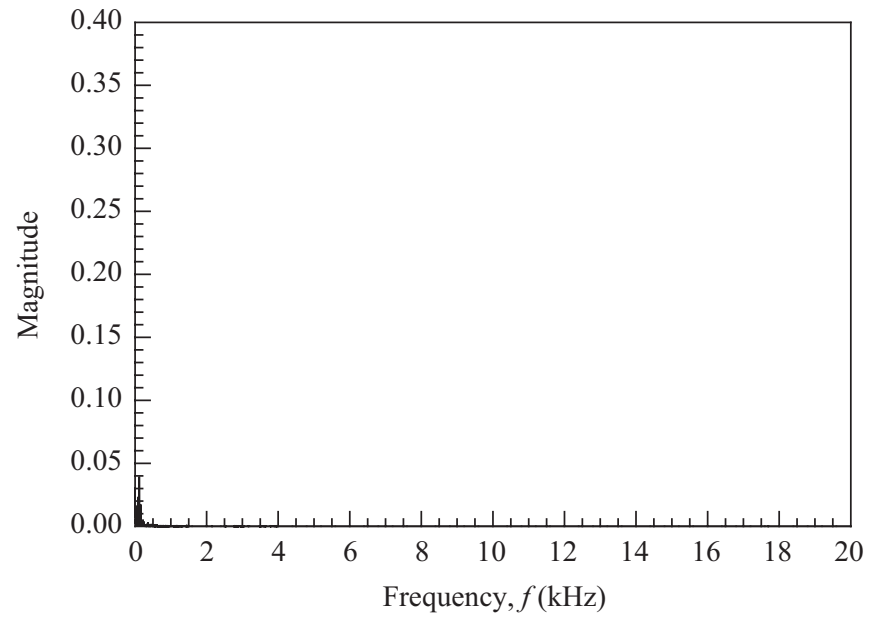

Fig. 7. Fourier spectrum of environmental noise.

interface. The transitional distance $\mathrm{S}$ from the dropping points to the actual interfaces were $9.0 \mathrm{~cm}$ and $8.7 \mathrm{~cm}$ for tests No. 1 and No. 2, respectively. The magnitude of $\mathrm{S}$ may be a function of soil type, including soil strength and compressibility, cone features, and penetration rate. As the cone tip entered the Jhongda Lateritic soil layer, cone resistance increases as depth increases. The cone resistances obtained in the Shiluo sand layer and Jhongda Lateritic soil layer were unstable, likely because of the shallow penetration depth in both soil layers. Furthermore, due to the existence of the transitional distance S, the position of the soil layer interface was not determined precisely. Hence, the cone resistance method is inadequate for determining the location of a soil interface.

\section{Background Noise Filtration}

In the acoustic CPT, background noise must be filtered out, such that the major responses of sound waves in soils can be visualized clearly. Villet [14] demonstrated that the frequency range of background noise generated during testing is mainly in the range of $0-1 \mathrm{kHz}$ and should be filtered out.

The background noise during the CPT can be divided into two types: (1) environmental noise; and, (2) mechanical noise produced by the penetration device. To distinguish differentiate between sound waves generated by the environment and mechanical noise, the acoustic cone was placed in air to measure its sound in both static and dynamic states. The environmental and mechanical noises were analyzed using the Fourier spectrum transform method (Figs. 7 and 8). The frequency band of both noise types were in the range of $0-1 \mathrm{kHz}$. The values of $P_{R M S}$ for environmental and mechanical noise were about $0.057 \mathrm{~Pa}$ and $0.450 \mathrm{~Pa}$, respectively. In other words, mechanical device noise was the predominant source of background noise. The principal frequency range of this mechanical noise was set as the filter-out threshold value for background noise. All analyses of sound results, such as sound pressure, $P_{R M S}$ and spectra, were filtered using this method. 


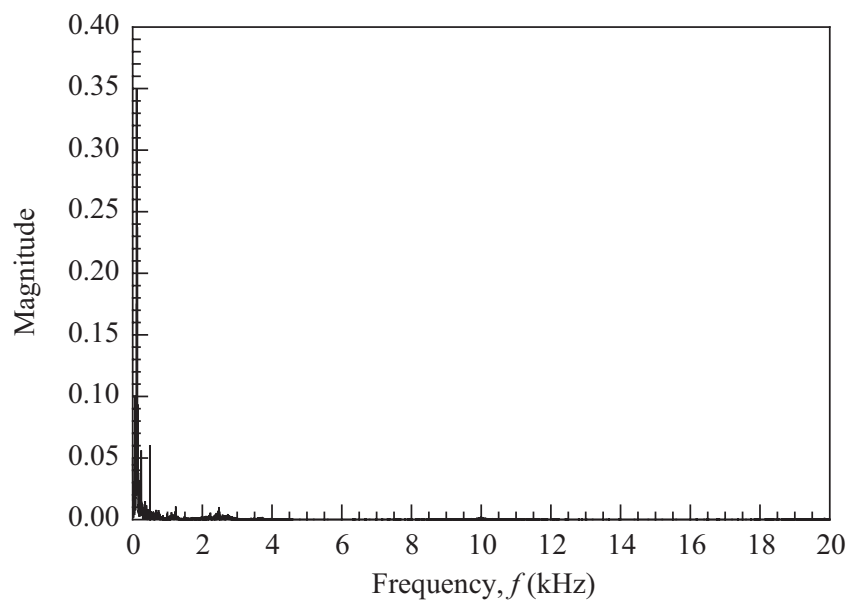

Fig. 8. Fourier spectrum of mechanical noise.

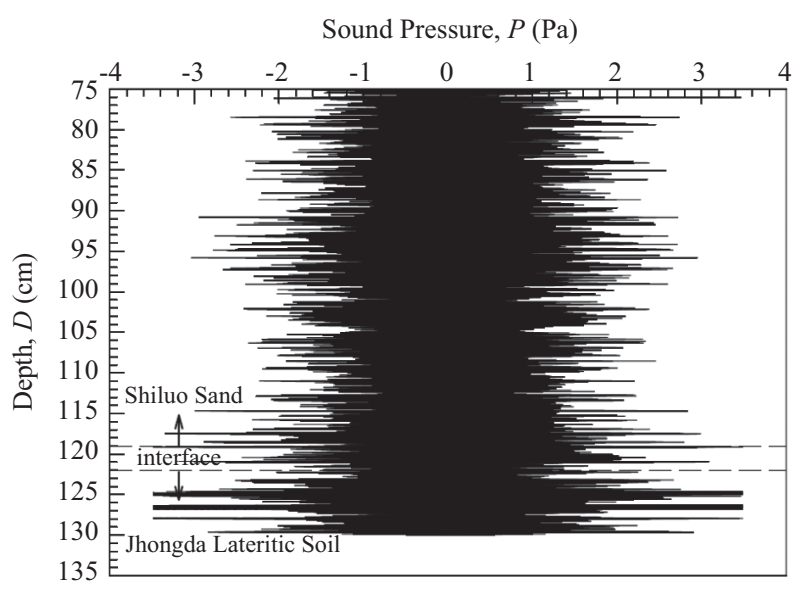

(a)

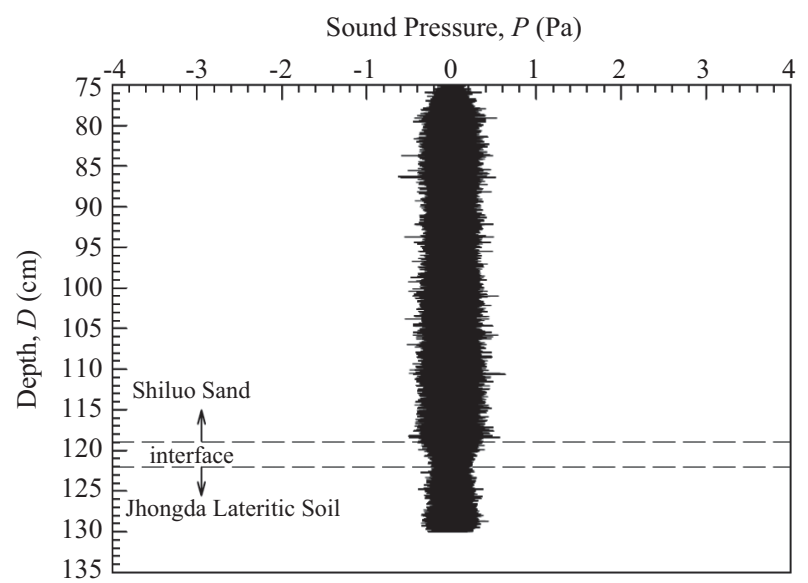

(b)

Fig. 9. (a) Relationship between original sound pressure and depth for test No. 1, (b) relationship between filtered sound pressure and depth for test No. 1.

\section{Filtered Sound Pressures}

This section describes the use of a highly sensitive microphone to enhance the accuracy in determining the interface

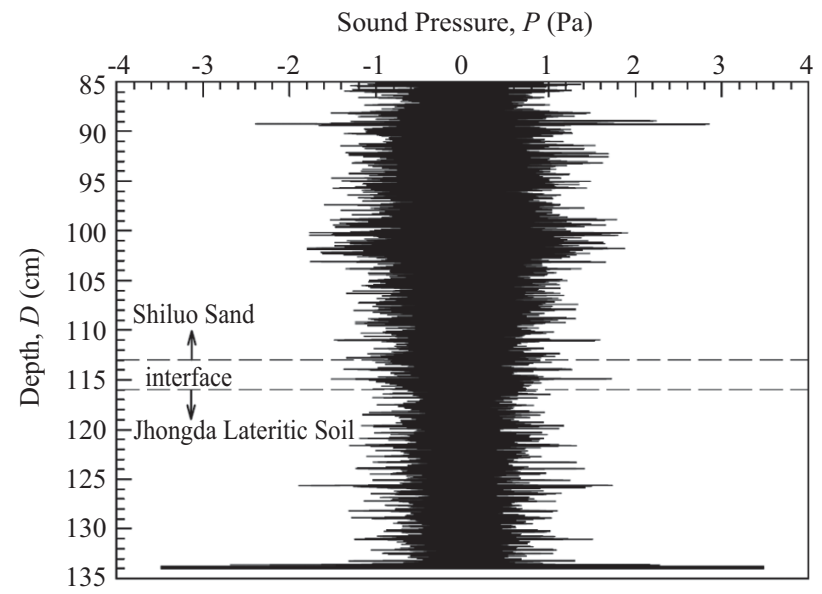

(a)

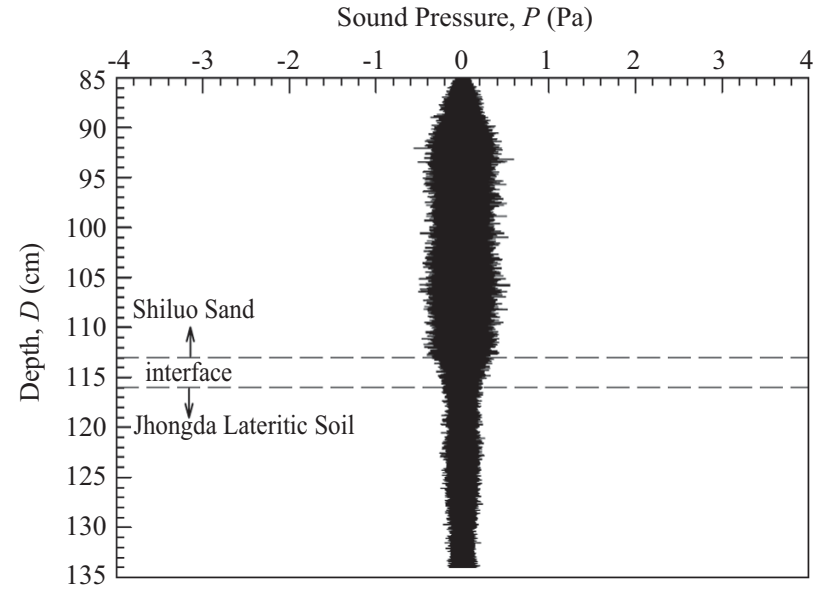

(b)

Fig. 10. (a) Relationship between original sound pressure and depth for test No. 2, (b) relationship between filtered sound pressure and depth for test No. 2.

position between soil layers. Further, the relationship between the sound waves and soil characteristics is established. The investigation of the distinction between the original sound pressure and filtered sound pressure was conducted when the cone penetrated the Shiluo sand layer and Jhongda Lateritic soil layer. Figures 9(a) and 9(b) show the distributions of the original and filtered sound pressures at various depths for test No. 1, respectively. The original sound pressure is chaotic and irregular (Fig. 9(a)). After noise filtration (Fig. 9(b)), the sound pressure of Shiluo sand layer is significantly different from those of Jhongda Lateritic soil layer at the interface. That is, the amplitude belt of the sound pressure remains at a constant wide range (about $\pm 0.45 \mathrm{~Pa}$ ) in the upper layer, and decreases drastically when the cone tip reaches depths of 119-122 cm. The sound pressure maintains a narrow range (about $\pm 0.3 \mathrm{~Pa}$ ) in the subsequent penetration. A similar experimental result was obtained in test No. 2 (Figs. 10(a) and 10(b)). The depths at which the amplitudes of filtered sound pressures change drastically correspond to those confirmed by excavation of the test pit. Hence, by using the filtered sound pressures, one can 


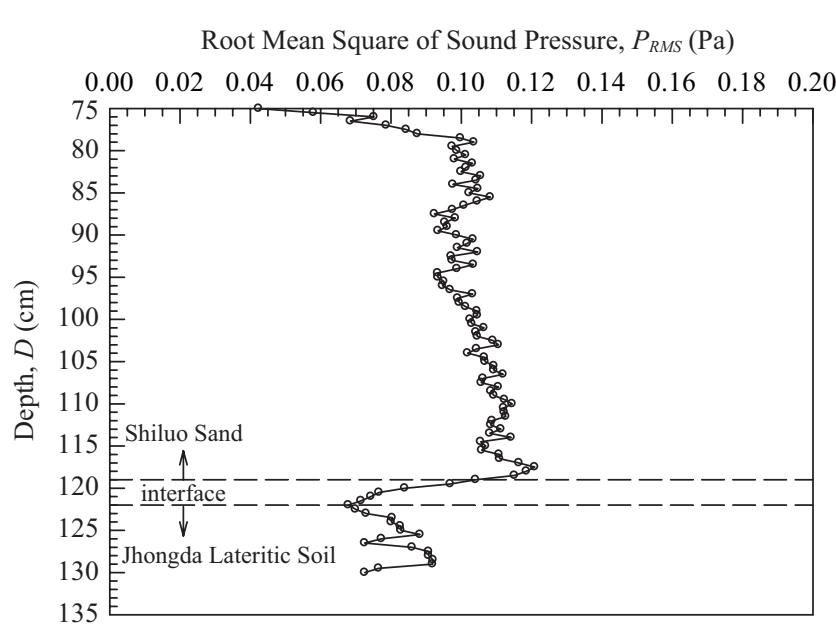

Fig. 11. Relationship between root mean square of sound pressure and depth for test No. 1.

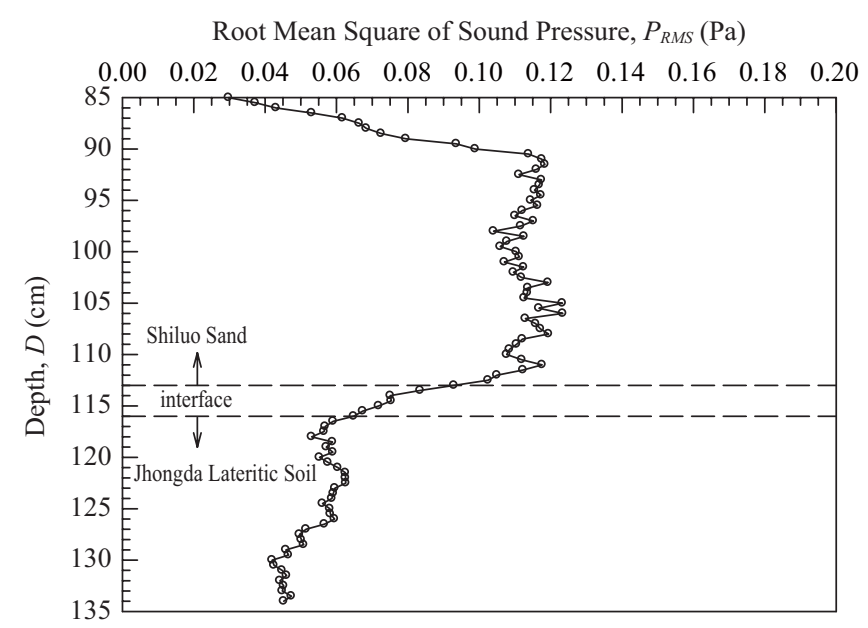

Fig. 12. Relationship between root mean square of sound pressure and depth for test No. 2.

precisely determine the interface position. In other words, the method using filtered sound pressure is more accurate than the cone resistance method.

\section{Root Mean Square of Sound Pressure}

This section discusses the RMS of sound pressure along penetration depths. The values of $P_{R M S}$ remain similar for tests No. 1 and No. 2 (Figs. 11 and 12). This phenomenon obviously differs from that of cone resistance. The values of $P_{R M S}$ in the Shiluo sand layer vary at $0.093-0.120 \mathrm{~Pa}$, and those in the Jhongda Lateritic soil layer vary at 0.068-0.092 Pa (Fig. 11). The test No. 2 (in Fig. 12) results have a similar tendency. That is, the $P_{R M S}$ responses of the Shiluo sand and Jhongda Lateritic soil are significantly different. The interface location between the Shiluo sand and Jhongda Lateritic soil can be determined because the value of $P_{R M S}$ decreased rapidly when the cone tip reached the interface; this was verified by sampling. A thin layer of mixed Shiluo sand and Jhongda Lateritic
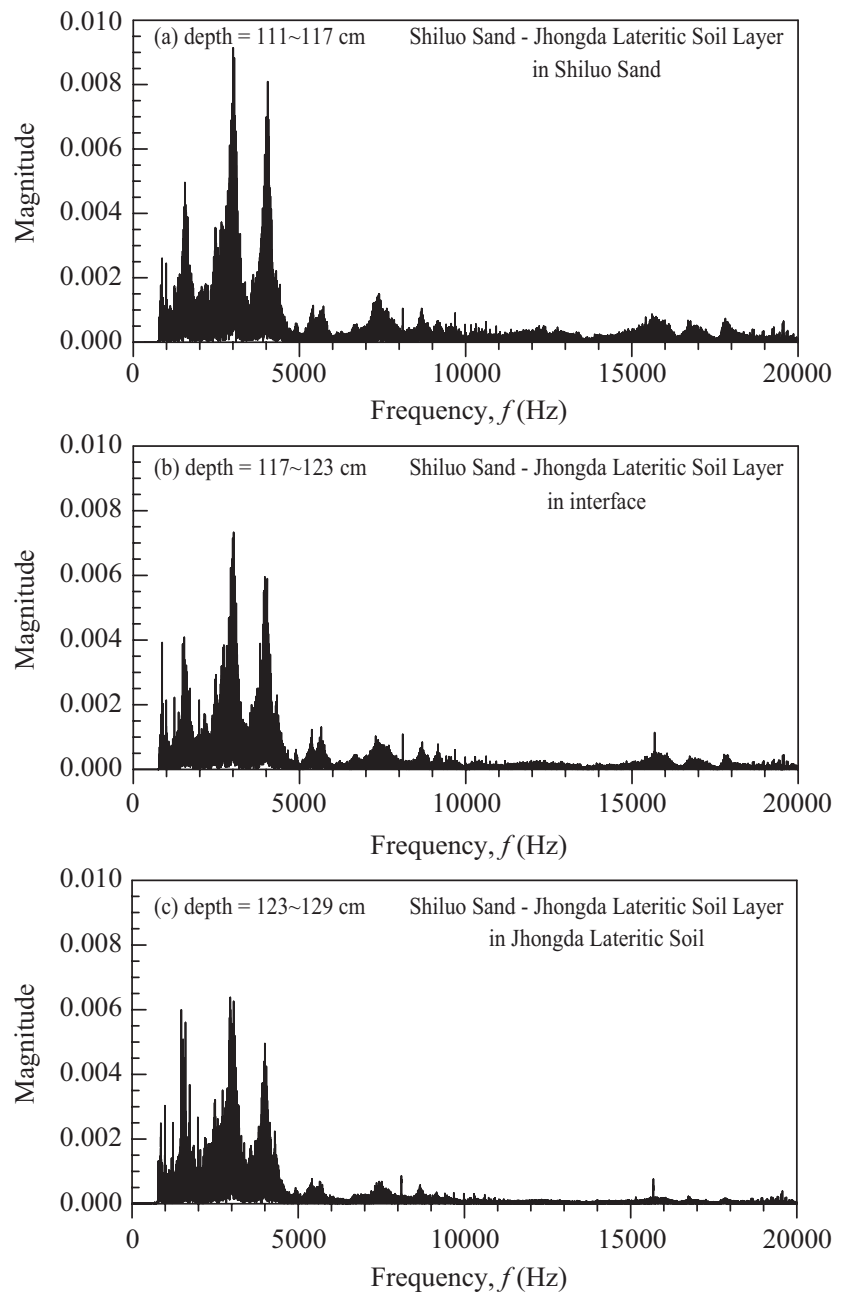

Fig. 13. Fourier spectra of filtered sound pressure from different depths for test No. 1.

soil exists at this location, meaning that the corresponding depth where $P_{R M S}$ values change rapidly is the interface location. These experimental results demonstrate that the mobile RMS method is an accurate and effective way of locating an interface between different soils. The effectiveness of mobile RMS method is superior to that of the cone resistance method.

\section{Fourier Spectrum Analysis}

Villet [14] determined that the main frequency range of sound waves generated due to soil particles rolling and sliding on the cone surface, or due to soil particles rolling and sliding over one another, is distributed in the low-frequency band, and the crushing of particles may cause the secondary frequency of sound waves. Figure 13 shows the distribution patterns of test No. 1 spectra, and Fig. 13(a) shows the spectrum of the Shiluo sand layer. Figures 13(b) and 13(c) show the spectra of the mixed interface and Jhongda Lateritic soil layer, respectively. The trends of energy distributions of sound waves are similar, with the predominant frequency band located in the range of $1.5-4.0 \mathrm{kHz}$. 

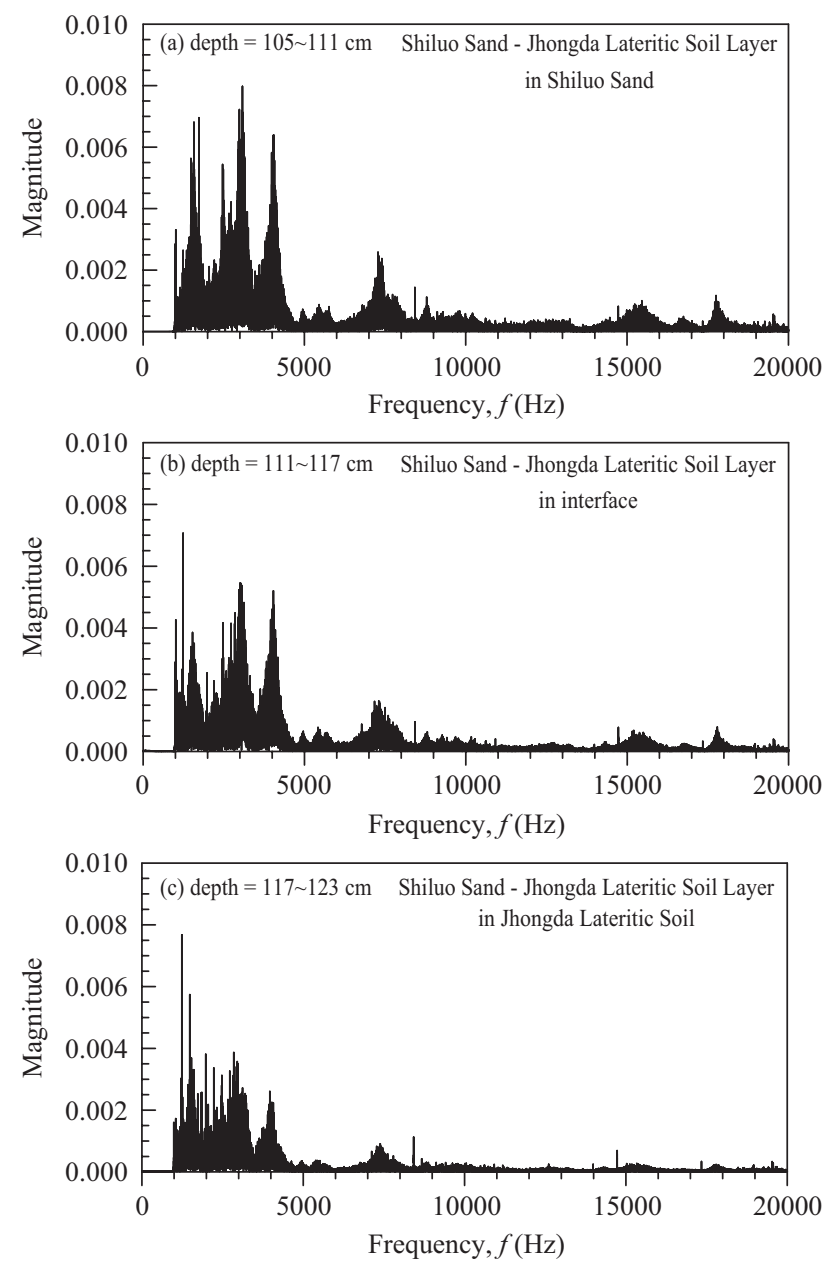

Fig. 14. Fourier spectra of filtered sound pressure from different depths for test No. 2.

Moreover, the energy (magnitude) of each frequency decreases gradually as penetration depth increases; that is, the highest amount of sound wave energy is created in the Shiluo sand layer, followed by that of the mixed interface layer and that in Jhongda Lateritic soil layer. A drop in peak magnitude energy in specific predominant frequencies exists in the range of 3-4 kHz. This phenomenon is clearly observed in test No. 2 results (Fig. 14). Nevertheless, due to complexity and variety of sound pressures, some transient changes occur within a short period (e.g., at the soil interface). Since the Fourier spectra only represent the overall frequency distribution for a particular time length, the relationship between frequency and time relative to depth is not determined. Hence, determining the instantaneous energy changes at some specific frequency from the Fourier spectrum is very difficult. Again, with the Fourier spectrum method, one cannot accurately locate the interface between the Shiluo sand and the Jhongda Lateritic soil layers.

\section{Hilbert-Huang Transform}

In this section, the analytical mode of the HHT for estab-

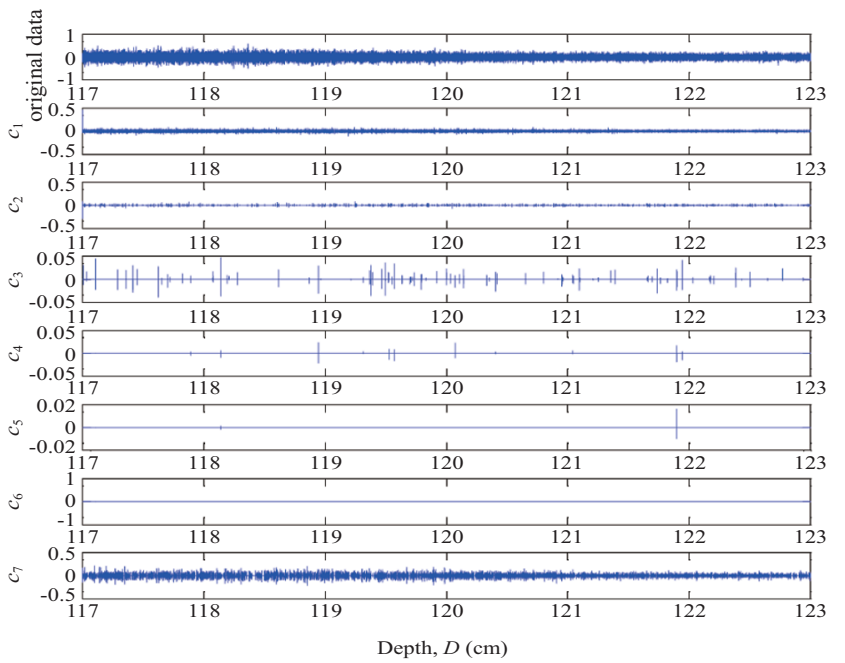

(a)

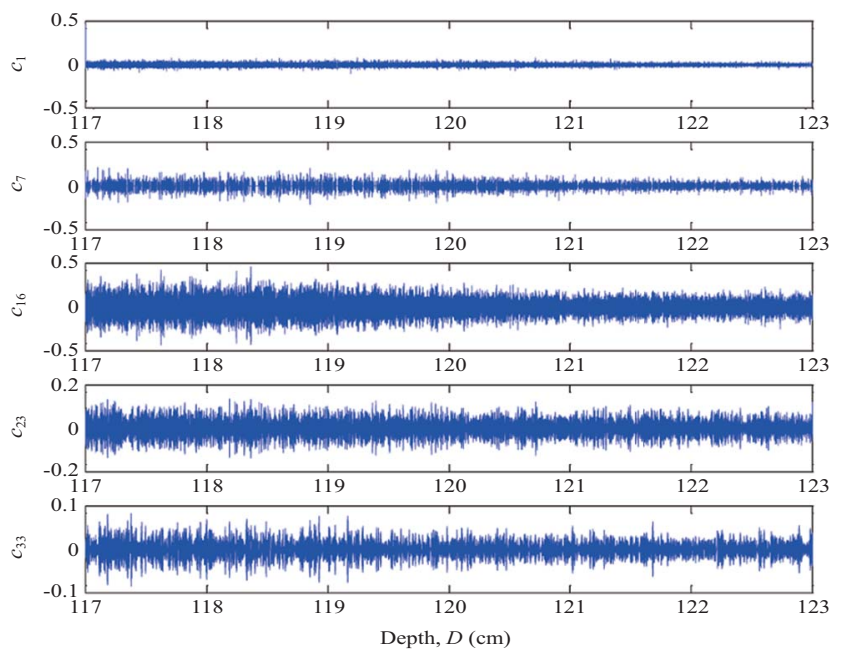

(b)

Fig. 15. (a) Original data and first seven IMFs of the interface for test No. 1, (b) 1st, 7th, 16th, 23rd and 33rd IMFs of the interface for test No. 1.

lishing the relationship between sound wave frequency and penetration time is discussed; the HHT can overcome the deficiencies of the FFT.

Since the actual location of interface between Shiluo sand and Jhongda Lateritic soil is confirmed by sampling, the sound signals obtained at depths of $117-123 \mathrm{~cm}$ in test No. 1 and $111-117 \mathrm{~cm}$ in test No. 2 are collected for HHT analysis. The HHT procedure and HHT analytical results are as follows.

(1) The filtered sound pressure, $P(t)$, data are utilized as input. First, this study selects the extreme EMD envelope obtained by the cubic spline. To avoid the mode mixing phenomenon, the intermittency method is utilized to carry out the EMD procedure. The data are decomposed into nintrinsic mode functions $c_{j}(t)$ in terms of an internal time scale and a residue $r_{n}(t)$, which can be either the mean trend or a constant. The function is expressed as 

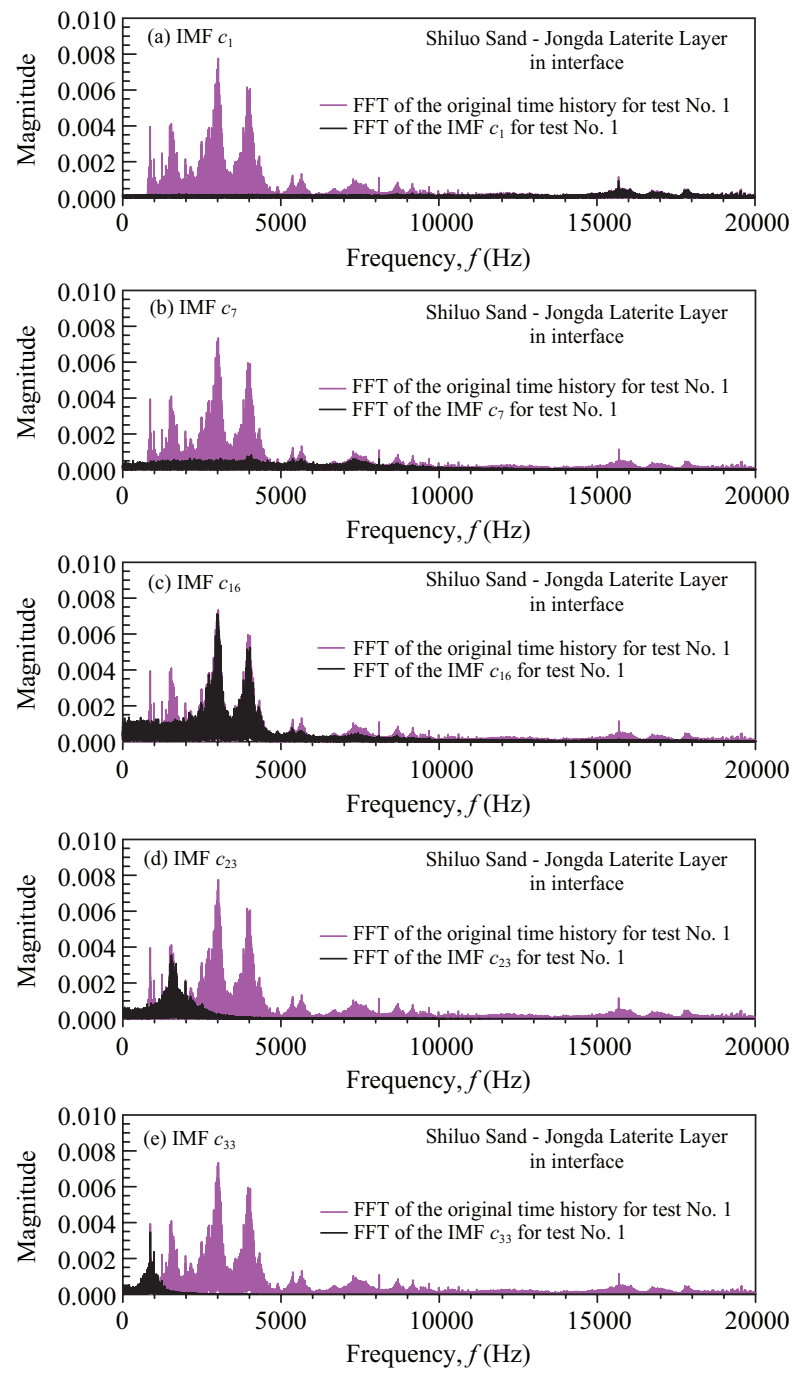

Fig. 16. Fourier spectra of different IMFs from the interface for test No. 1.

$$
P(t)=\sum_{j=1}^{n} c_{j}(t)+r_{n}(t)
$$

In total, 94 intrinsic mode functions are separated from the data for test No. 1. Figure 15(a) shows the original filtered sound pressure and first seven IMFs, where $c_{n}$ is the nth component of the IMF. Figure 15(b) shows the 1st, 7th, 16th, 23rd and 33rd IMF components. For observational and comparison convenience, the time scale of the above figures is transformed into a depth scale based on a penetration rate of $2 \mathrm{~cm} / \mathrm{sec}$. In test No. 1, the $1 \mathrm{st}$, 7th, 16th, 23rd and 33rd components of IMFs are selected for analysis for the followings reasons.

A. The characteristics of IMFs selected (Figs. 15(a) and 15(b)) are very similar to those of the original filtered sound pressures; other components are not utilized as they are disordered, irregular or bursting signals with small amplitudes.

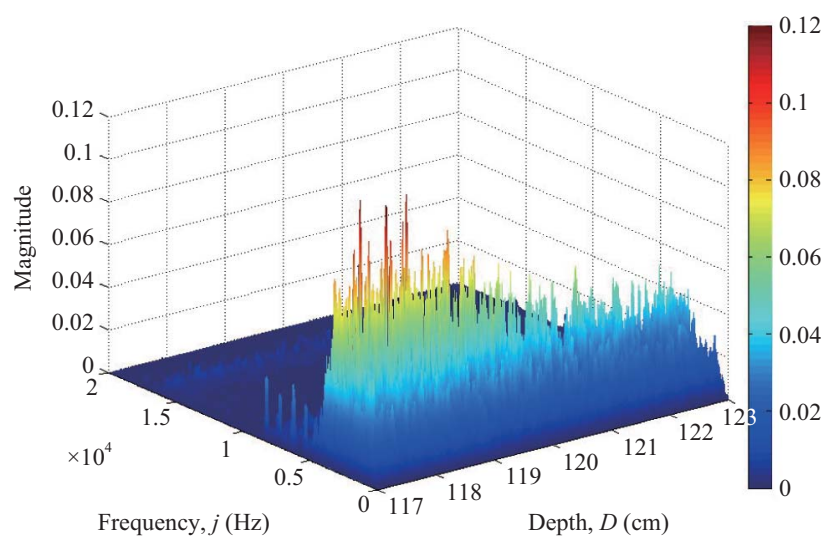

Fig. 17. Hilbert spectra of the interface for test No. 1.

B. Figure 16 shows the Fourier spectra of the $1 \mathrm{st}\left(c_{1}\right), 7$ th $\left(c_{7}\right)$, 16th $\left(c_{16}\right), 23 \mathrm{rd}\left(c_{23}\right)$ and 33rd $\left(c_{33}\right)$ IMF components. As the selected IMFs cover the energy of certain predominant frequencies, these IMF components can be used to present the principal characteristics of filtered sound pressure. The Fourier spectra frequencies of IMF components of numbers $>33$ are $<1 \mathrm{kHz}$, and, therefore, not used in this study.

Based on the above rationale, the physical meanings of selected IMFs are verified. Data from test No. 2 are treated in the same manner and similar analytical results are obtained.

(2) Based on the above preparation of IMFs, the Hilbert transformation is applied to obtain a three-dimensional Hilbert spectrum (time-frequency-energy distribution). Figure 17 shows the Hilbert spectrum of test No. 1, which indicates that the predominant frequency is in the range of 3-4 kHz. Furthermore, the magnitude of the Hilbert spectrum remains constant at a large value at depths of $117-119 \mathrm{~cm}$, decreases drastically when depth exceeds $119 \mathrm{~cm}$ and remains at a small value when depth exceeds $122 \mathrm{~cm}$. A similar tendency of the Hilbert spectrum in test No. 2 is identified, while variation in the magnitude range occurs at depths of 113-116 cm (Fig. 18). These HHT results are consistent with those obtained from filtered sound pressures and the mobile RMS results. However, although the filtering process is applied, the filtered sound pressure and mobile RMS results still contain a few high frequency bands of environmental noise. The specific high frequency can be filtered out using the HHT. Only when the magnitude of the predominant frequency band is filtered out, the analytical results accurately reflect the major variation and distribution of sound signals produced by rolling and sliding soil particles at the cone surface and the friction between soil particles. This can be achieved by the HHT method, not by filtering sound pressure or the mobile RMS method. Nevertheless, in terms of convenience, the HHT procedure is more complex than the other two methods. In this study, the HHT results are used to 


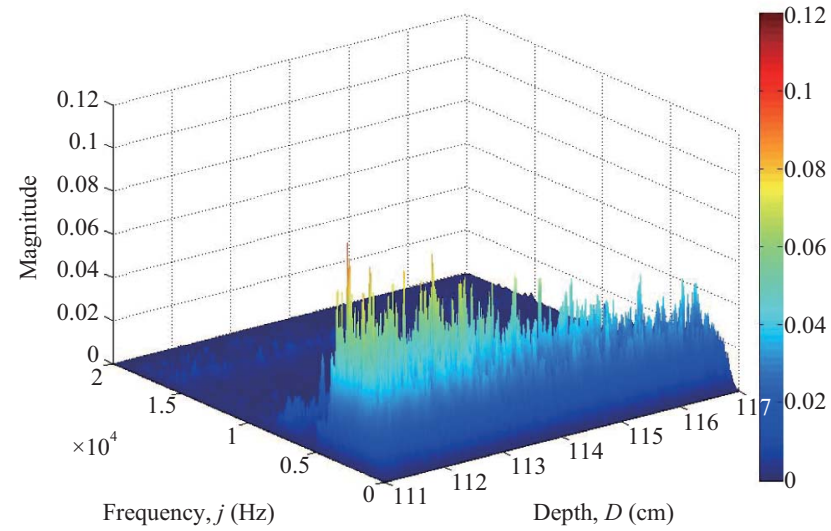

Fig. 18. Hilbert spectra of the interface for test No. 2.

verify the accuracy of filtered sound pressure and the mobile RMS method.

\section{CONCLUSIONS}

In this study, sound waves are measured via the CPT to demonstrate the applicability of the acoustic cone method for site investigation. Different analytical methods, such as cone resistance, filtered sound pressure, mobile RMS, the Fourier spectrum and Hilbert spectrum, are utilized to establish relationships between sound waves and soil types. The principal conclusions are as follows.

(1) Uncertainty exists when using cone resistance to determine the location of a soil layer interface. However, the position of the interface can be detected clearly, easily and effectively using the mobile RMS method. The advantages and accuracy of this method are better than that of the cone resistance method.

(2) Analytical results of the Fourier spectra indicate that the predominant frequency band of the Shiluo sand layer and Jhongda Lateritic soil layer is in the range of 1.5-4.0 kHz. Additionally, the magnitude of the predominant frequency in the Shiluo sand layer is higher than that in the Jhongda Lateritic soil layer.

(3) The Fourier spectra cannot precisely locate the interface between different soil layers. The HHT results show significant variation in the magnitude of the predominant frequency $(3-4 \mathrm{kHz})$ at the soil interface. The magnitude difference in the predominant frequency between the Shiluo sand layer and Jhongda Lateritic soil layer can be utilized to accurately determine the soil interface position. These HHT results provide important physical meanings, but the process is too complex.

(4) Overall, the mobile RMS method may be the best application for interface identification in terms of both precision and convenience.

(5) The major contribution of this study is that it uses the RMS of sound wave as a more accurate, effective and easy method for exploration of soil distribution and detection of soil interfaces.

\section{ACKNOWLEDGMENTS}

The authors would like to thank the National Science Council of the Republic of China, Taiwan, for financially supporting this research under Contract No. NSC 89-2211-E-008-098.

\section{REFERENCES}

1. Bi, D. C., Application of Hilbert Spectrum in Seismic Data, Master's Thesis, Department of Civil Engineering, National Central University, Jhongli (2000).

2. Chang, H. W. and Ou, Z. Z., The Cone Penetration Device of Reaction Type, R.O.C. Patent, Type B, No. 69309 (1991).

3. Chuang, C. Y., Application of Acoustic Emission in the Cone Penetration Test, Master's Thesis, Department of Civil Engineering, National Central University, Jhongli (1996).

4. Hazen, A., Water Supply, in American Civil Engineering Handbook, Wiley, New York (1930).

5. Hsieh, C. M., Introduction of Hilbert-Huang Transform, handouts, Institute of Navigation Science and Technology, National Kaohsiung Marine University, Kaohsiung, pp. 6-8 (2007).

6. Huang, N. E. and Shen, S. S. P., Hilbert-Huang Transform and It's Applications, Word Scientific Publishing Co. Pte. Ltd., Singapore, pp. 4-14 (2005).

7. Huang, N. E., Shen, Z., Long, S. R., Wu, M. C., Shih, H. H., Zheng, Q., Yen, N. C., Tung, C. C., and Liu, H. H., "The empirical mode decomposition and the Hilbert spectrum for nonlinear and nonstationary time series analysis," Proceedings of Royal Society of London, Series A 454, pp. 903-995 (1998).

8. Koerner, R. M., Mccabe, W. M., and Lord, A. E., "Acoustic emission behavior and monitoring of soils," Acoustic Emissions in Geotechnical Engineering Practice, ASTM STP 750, American Society for Testing and Materials, pp. 93-141 (1981).

9. Lin, Y. H., Acoustic Emission Characteristics in Saturated Sand by Using Acoustic Cone Penetration Test, Master Thesis, Department of Civil Engineering, National Central University, Jhongli (2003).

10. Massarsch, K. R., "Acoustic penetration testing," Proceeding of the 4th Geotechnical Seminar, Field Instrumentation and In-situ Measurements, Nanyang Tech. Inst., Singapore, pp. $71-76$ (1986).

11. Schmertmann, J. H., Guidelines for Cone Penetration Test, Performance a Design, Federal Highway Administration Report No. FHWA-TS-78209, U.S. Department of Transportation, Washington, D. C., p. 145 (1978).

12. Tanimoto, Y. and Tanaka, Y., "Study of acoustic emission due to deformation of sandy soil," Soils and Foundations, Vol. 35, No. 4, pp. 55-60 (1987).

13. Tringale, P. T., Soil Identification In-site Using an Acoustic Cone Penetrometer, Ph.D. Dissertation, University of California, Berkeley (1983).

14. Villet, W. C. B., Acoustic Emissions during the Static Penetration of Soils, Ph.D. Dissertation, University of California, Berkeley (1981).

15. Wang, S. C., Seismic Records Analysis of Liyutan Earth Dam, Master's Thesis, Department of Civil Engineering, National Central University, Jhongli (2003).

16. Wang, Z. W., A Study of Acoustic Cone Penetration Test on Acoustic Emission Characteristics of Soil, Master Thesis, Department of Civil Engineering, National Central University, Jhongli (2002).

17. Xu, W. Z., Noise and Vibration Control, Xie-Zhi Industry Series, Taipei, pp. 100-106 (1984).

18. Yang, F. C., A Study of Surface Wind Pressure on the Structure in Gust Field by Using Hilbert-Huang Transform, Master's Thesis, Department of Civil Engineering, National Central University, Jhongli (2005). 